\title{
RHIC RF SYSTEMS
}

H. Halama

\section{Brookhaven National Laboratory}

March 9, 1984 
RHIC RF Syster IMV/tum

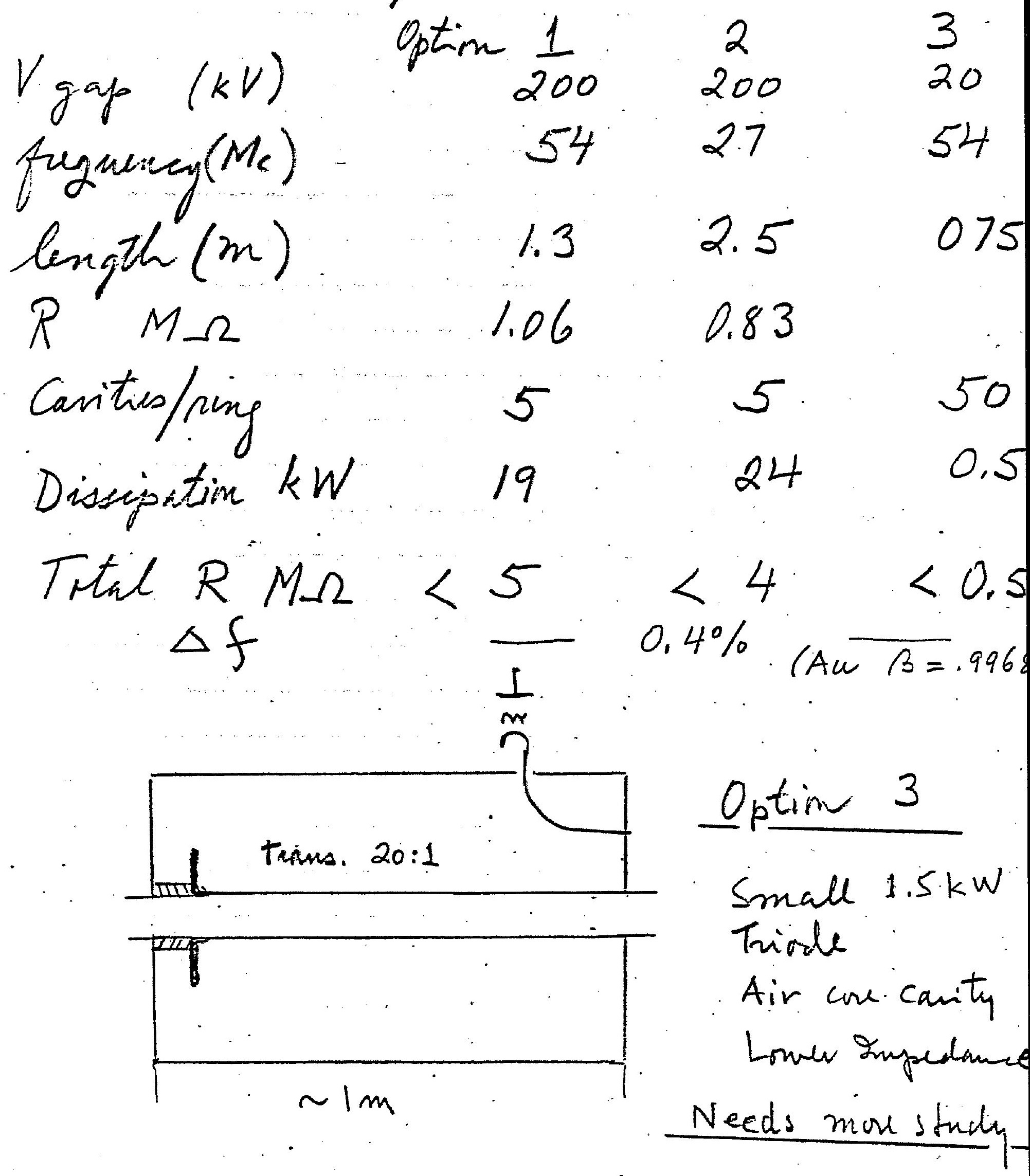


Power Losses

$$
\begin{aligned}
& W=\frac{1}{2} R_{s}\left(\frac{V}{Z_{0}}\right)^{2} \frac{1}{16 \pi}\left(\frac{\lambda}{R_{1}}+\frac{\lambda}{R_{3}}\right) \\
& \omega \propto \sqrt{\lambda} \\
& \Longrightarrow R_{1} R_{3} \\
& f \text { (length) } \\
& y_{4} \quad 1 \\
& 2 / 8 \quad 1.6 \\
& 4 / 16 \quad 3.3 \\
& f\left(\frac{R_{3}}{R_{1}}\right) \\
& \min \frac{R_{3}}{R_{1}}=9 \\
& \text { w } \\
& \text { I } \\
& \frac{R_{3}}{R}=3 \cdot 1.65
\end{aligned}
$$




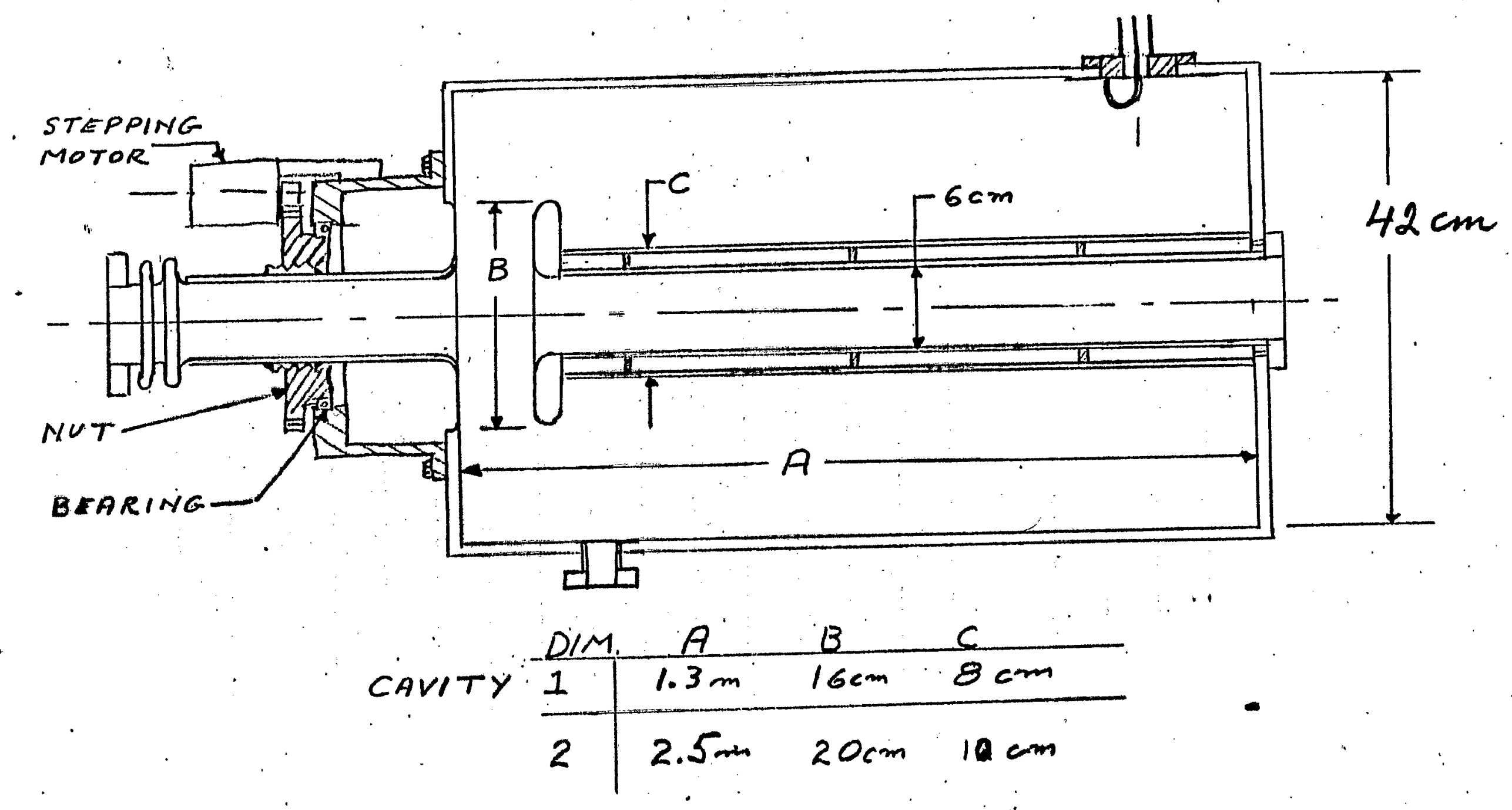

SKETCH OF HRIC RF CAVITY 